\title{
ON EXPORTS AND PRODUCTIVITY: A CAUSAL ANALYSIS
}

\author{
Robert M. Kunst and Dalia Marin*
}

\begin{abstract}
The causes of the wide variation in growth rates between countries have been debated by theorists of economic growth. Different studies have shown these disparities between growth rates largely to have been caused by different rates of increase in productivity per unit of factor input. The observed comovement between productıvity and export growth suggest a direct link between these two variables. The paper explores the causal relationship between productivity and exports based on Austrian data using time series analysis. The causality analysis indicates no causal link from exports to productivity while the null of no causality from productivity to exports has to be rejected at conventional levels
\end{abstract}

\section{Introduction}

The causes of the wide variation in growth rates between countries have been debated by theorists of economic growth. Different studies have shown these disparities between growth rates to be only in part explainable by different rates of increase in the employment of the basic factors of production, capital and labour. The main conclusion to be drawn from these studies is that the diversity in growth rates between countries was largely caused by different rates of increase in productivity per unit of factor input. The observed positive association between productivity growth and export growth led to two causal hypotheses. The first assumes productivity to be largely induced by demand prospects via export growth, while the second considers productivity to determine the rate of growth of exports and to be independent of export demand.

The direction of causation between exports and productivity has important implications for the way industrial policy can stimulate productivity growth. While the export-productivity link given by the export-led growth model suggests an export promoting policy, e.g., by a depreciation of the exchange rate and/or an export subsidy, the link described by the technology based international trade models and some recent trade theories considers an $\mathrm{R} \& \mathrm{D}$ and/or an output subsidy as more effective to stimulate productivity growth.

This paper explores with Austrian data which of the above hypotheses are compatible with the observed

Received for publication October 23, 1986. Revision accepted for publication November 2, 1988.

*Institute for Advanced Studies; and Institute for Advanced Studies and European University Institute, respectively.

We are grateful to $\mathrm{K}$ C. Fung, and an anonymous referee for helpful comments on an earlier version. movements between exports, productivity, the terms of trade, and world output. The causal ordering between these series will be identified on the basis of Granger's concept of causality, leaving aside the debate on the meaning of the test itself (see Leamer (1985)).

A considerable number of time series studies in recent years have concentrated on the investigation of the causal relationship between money and income (pioneered by Sims (1972)) on the one hand and the causation between employment and the real wage on the other (Ashenfelter and Card (1982)). In contrast, the direction of causation between exports and productivity has not been subjected to empirical tests of this sort up to now.

The paper is organized as follows. In section II the theoretical link between exports and productivity as provided by different theories will be briefly discussed. Section III gives a review of Granger's concept of causality and describes the test design pursued. In section IV the time series data are presented in multivariate autoregressive form and the results of various causality tests are shown. Finally, section V summarizes the findings and draws tentative policy implications.

\section{Causal Explanations}

The export-led growth models to be found in the literature on applied growth theory stress the hypothesis that exports are a key factor in promoting productivity growth. Several explanations for the causal link between exports and productivity were put forward. First, exports are seen to concentrate investment in the most efficient sectors of the economy-those in which the country enjoys a comparative advantage. Stronger specialization in these sectors is seen to increase productivity. Second, higher export growth is viewed to allow the country to gain from economies of scale as the inclusion of the international market to the domestic market is seen to permit larger scale operations than does the domestic market alone. Third, stronger exposure to international competition by higher exports is considered to increase the pressure on the export industries to keep costs low and provide incentives for the introduction of technological change which improves productivity. Fourth, the growth of exports is seen to have a stimulating influence on productivity of the economy as a whole via externalities of exports on other sectors. ${ }^{1}$

\footnotetext{
${ }^{1}$ For a summary see Bhagwati (1978).
} 
Although the export-led growth hypothesis has been originally developed for industrialized countries (see Beckerman (1965)), most studies confined the test of the hypothesis on developing countries (see Balassa (1978), Feder (1982), and Michaely (1977)). However, there does not seem to be any a priori reason why the structural relationship should not hold for developed countries as well. ${ }^{2}$

Compared to the export-led growth models, the technology theories of trade propose a causal link which runs from productivity to trade rather than vice versa. Competitive performance in export markets is attributed by these models to market power achieved through innovation (see Vernon (1966)).

While the export-led growth models and the technology-oriented theories of trade stress one direction in the causal relationship between exports and productivity,

$$
\Phi(L)\left[\begin{array}{l}
X_{t} \\
Y_{t} \\
Z_{t} \\
W_{t}
\end{array}\right]=\left[\begin{array}{ll}
\Phi_{11}(L) & \Phi_{12}(L) \\
\Phi_{21}(L) & \Phi_{22}(L) \\
\Phi_{31}(L) & \Phi_{32}(L) \\
0 & 0
\end{array}\right.
$$

recent theories of intra-industry trade suggest a causal link between productivity and exports in both directions. These theories incorporating imperfect competition, economies of scale and product differentiation consider productivity increases through the realization of static economies of scale as the cause of trade between countries with similar factor endowments. Besides the positive causal influence of scale economies on exports, trade will tend to increase average productivity of a country, if in response to a disturbance the market structure changes towards fewer firms, more concentrated declining cost industries and a larger proportion of resources in declining cost industries. ${ }^{3}$

In spite of these potential productivity effects from trade it can be shown that under an oligopolistic market structure with Cournot conduct an import protection can lead to productivity gains which act as export promotion (Krugman (1984)). An import tariff (or a quota) leads to a productivity gain by allowing domestic sales to expand, which translates into higher shares of the home firms on foreign markets. Accordingly, a deterioration in the terms of trade (through an import tariff and/or an exchange rate devaluation) is supposed to result in a productivity and export increase.

The paper performs a statistical test of the causal hypotheses implied by the models of this section without claiming to test the theories. The results indicate

\footnotetext{
${ }^{2}$ A recent study which includes developed market economies is Helpman and Trajtenberg (1987).

${ }^{3}$ See Helpman and Krugman (1985).
}

whether the data contradict or are compatible with the new causal hypotheses.

\section{Testing Granger Causality}

Granger (1969) defined his statistical concept of causality as follows. Given a universe including the two series $\left(X_{t}\right)$ and $\left(Y_{t}\right), X$ is said to cause $Y$ if the forecast for $Y_{t}$ from the history of the universe excluding $X$ can be improved by taking the history of $X$ into account.

In this paper two different operationalizations of this definition are pursued. Both approaches are based on the original Granger procedure and are applied to universes consisting of four series. Let $\left(X_{t}, Y_{t}, Z_{t}, W_{t}\right)$ be a four-dimensional (covariance-) stationary process with $W_{t}$ only depending on its own past. Assume a finite multivariate autoregressive (AR) representation exists:

$$
\left.\begin{array}{ll}
\Phi_{13}(L) & \Phi_{14}(L) \\
\Phi_{23}(L) & \Phi_{24}(L) \\
\Phi_{33}(L) & \Phi_{34}(L) \\
0 & \Phi_{44}(L)
\end{array}\right]\left[\begin{array}{c}
X_{t} \\
Y_{t} \\
Z_{t} \\
W_{t}
\end{array}\right]=\left[\begin{array}{c}
e_{1 t} \\
e_{2 t} \\
e_{3 t} \\
e_{4 t}
\end{array}\right]
$$

$\left(e_{1 t}, e_{2 t}, e_{3 t}, e_{4 t}\right)^{\prime}$ jointly white noise. In order to make (1) identified, it is further assumed that the matrix of the zero-order coefficients of $\Phi(L)$ be the identity matrix, i.e., $\Phi_{i j, 0}=\delta_{i j}$.

Granger causality may be investigated by testing the off-diagonal elements of $\Phi(L)$ to be different from zero polynomials. For instance, " $Y$ causes $X$ " may be tested by the $\Phi_{12}$ polynomial, " $Z$ causes $X$ " by $\Phi_{13}$ etc. Tests for polynomial zeros may be carried out by testing the joint significance of the corresponding lag coefficients, that is, by likelihood-ratio tests or operational approximations such as the usual $F$-statistics of OLS regression.

The two testing methods differ with regard to the specification of the AR models (1). Causal directions often rely on just a few lags $\Phi_{\imath, k}$ of the source variable. If those lags are ignored in the model the test procedure necessarily fails to detect causality. On the other hand, excluding lags in the $\Phi_{u}$ might shift explaining power to the off-diagonal polynomials, thereby generating spurious causality. Due to the finiteness of the sample at least some restrictions have to be specified. For the diagonal elements, the optimal univariate autoregressive models chosen by the Akaike Information Criterion (AIC) offer themselves as a starting point. ${ }^{4}$ In the first testing approach, the maximal lag for the off-diagonals

\footnotetext{
${ }^{4}$ AIC was defined by Akaike (1974) to be the sum of $T$ times the logged residual variance plus twice the number of parameters contained in the model. Additional parameters reduce the first term and increase the second, eventually producing a minimum which is then used ( $T$ denotes the sample size).
} 
was set to four in accordance with the quarterly data and with the requirements concerning the degrees of freedom. In this approach, henceforth denoted UVAR (for $u$ nrestricted $v$ ector $a$ utoregression), no further restrictions on the lag structure were imposed.

The UVAR design involves a high risk of ignoring significant lags in the off-diagonal polynomials, so that existing causal influences might not be detected. As a further increase of the model's dimension might lead to an inflation of insignificant parameters, near-multicollinearity and loss of degrees of freedom, more sensitive modelling, either in a Bayesian fashion or by zero restrictions taken from the data, is required ("subset models").

As the second test procedure, a subset model was built. Variable (subset) selection started from a maximal model obtained by setting the maximal lag of the $\Phi_{u}$ to the one identified by univariate AIC and of the offdiagonals to 8 . Since AIC evaluations of all possible subset models would have required an excessive amount of computer time, we used elimination ("backward search") based on consecutive omission of the least significant regressor within each of the single equations and calculation of the resulting AIC values. After thereby reaching a minimal model, eliminated regressors were re-scanned for possible significant influences ("forward search"). The resulting model is denoted as SMAR (for $s$ ubset model $A R$ ). Although the imposition of zero restrictions is sometimes criticized, there is now growing empirical evidence for subset models outperforming unrestricted vector-AR (Kunst and Neusser (1986)).

The power of the procedures relies on the assumption of correctly specified AR models and stationarity of the data. In order to remove all possible non-stationarities, all series were detrended by first logarithmic differences and seasonally adjusted by quarterly dummies. ${ }^{5}$

\section{Time Series Representation of Exports, Productivity, the Terms of Trade and World Output}

\section{A. Data}

In order to compare the causal predictions implied by the models described in section II with the Austrian facts, data for exports, price competitiveness, productivity and world output were required. We have used exports of manufactured goods as the export variable and the terms of trade (export unit value divided by import unit value for manufactured goods) in home currency as a measure for price competitiveness. Pro-

\footnotetext{
${ }^{5}$ The seasonal constants have been included in the AIC specification search.
}

Table 1 - Causality Tests for Productivity, Exports AND TERMS OF TRADE (UVAR-MODEL) ${ }^{a}$

\begin{tabular}{crcc}
\hline $\begin{array}{c}\text { Test for } \\
\text { Causality of }\end{array}$ & By & $\begin{array}{c}\text { Test } \\
\text { Statistic }^{\mathrm{b}}\end{array}$ & $\begin{array}{c}\text { Prob- } \\
\text { Value }^{\mathrm{c}}\end{array}$ \\
\hline PROD & $P T R$ & 07 & 58.22 \\
& $X G$ & 1.3 & 29.82 \\
& $Q$ & 44 & 036 \\
$X G$ & $P R O D$ & 2.1 & 9.04 \\
& $P T R$ & 1.5 & 2109 \\
& $Q$ & 1.9 & 12.32 \\
PTR & $P R O D$ & 2.6 & 4.54 \\
& $X G$ & 1.7 & 15.66 \\
& $Q$ & 2.4 & 61 \\
\hline
\end{tabular}

${ }^{a}$ All regressions cover 1965 2-1985 4

${ }^{b}$ The causality test statistic is an $F$-ratio for the null hypothesis that the coefficients of four lagged values of each of the variables in the second column are jointly equal to zero The number of lagged values of the dependent variable included in the regression equals that obtaned by the AIC criterion

${ }^{c}$ Probability of obtaining an F-ratio at least as large as the test statist:c under the null hypothesis A prob-value smaller than 5 indicates rejection of the null hypothesis at the $5 \%$ significance level

ductivity is measured by output per employee in the manufacturing sector. This measure of labour productivity reflects mainly static economies of scale as the capital coefficient has been approximately constant over the sample period and the trend has been removed from the data. ${ }^{6}$ In order to control for export growth which results neither from productivity nor from price competitiveness but from growth in the world economy, GDP of the OECD countries is included in the time series analysis.

\section{B. Causality in an Unrestricted Vector Autoregression (UVAR) Framework}

In table 1 the formal causality tests for productivity $(P R O D)$, exports $(X G)$, the terms of trade $(P T R)$ and OECD output $(Q)$ are shown. The causality test was obtained by first fitting the four variable vector autoregression by least squares over the sample period using the AIC criterion to determine the lag structure for the diagonal elements and including four lags for the offdiagonals. ${ }^{7}$ Then $F$-tests for the null hypothesis that the coefficients of the four lagged values of each of the variables are jointly equal to zero were performed. As can be seen from table 1 the $F$-ratios and prob-values to test whether productivity is Granger-caused by exports, OECD output, and the terms of trade indicate that OECD output causes productivity while the causation

\footnotetext{
${ }^{6}$ Between 1956 and 1982 the average annual growth rate of the capital output ratio is $0.5 \%$.

The estimated parameters are not reported and are available on request. The causal impact of Austrian variables on OECD output is not investigated as Austria as a small country is not considered to be able to influence world output.
} 
of exports and the terms of trade, respectively, on productivity are a great deal short of statistical significance.

While the test that productivity Granger-causes exports is statistically significant at the $10 \%$ level, the evidence that price competitiveness and OECD output cause exports is weak. The causality test for the terms of trade suggests a causal link from productivity and OECD output, respectively, on the terms of trade and no causation from exports on the terms of trade.

\section{Subset Model Autoregression (SMAR)}

As stated in section III, the UVAR test procedure has its weakness. An export stimulus might need some time to work through the system until it boosts productivity so that the absence of any causal impact of exports on productivity shown in table 1 might have been caused by too short a lag structure selected, as the different links suggested by the literature might take longer to be realized than one year. Moreover, many of the included four lags in each variable were insignificant at the $5 \%$ level suggesting that a different lag structure might be statistically more adequate. Therefore, we performed alternatively the SMAR which differs from the UVAR approach by restricting statistically insignificant lags to zero and by allowing up to eight lags for the off-diagonal elements in order to account for medium term influences.

A first look at table 2, which reports the results of the subset model vector autoregression for exports $(X G)$, productivity $(P R O D)$, and the terms of trade $(P T R)$, however, reveals that medium-term effects are only at work in the regression for the terms of trade, while for the remaining equations the overall picture seems not to have been changed substantially. The first column of table 2 indicates that the second quarter lagged productivity, the second quarter lagged price competitiveness and the first, fifth and seventh quarter lagged OECD output have a significant influence on exports. ${ }^{8}$ Thus, the UVAR as well as the SMAR test suggest that the Austrian data are compatible with the causal predictions implied by the theories of intra-industry trade as exports are Granger-caused by productivity.

From column 2 of table 2 emerges that the SMAR procedure made the lagged coefficients of exports and the terms of trade disappear altogether from the productivity equation. Only the first lagged OECD output has a significant influence on productivity which confirms the result of the UVAR test. Thus, the extension of the lag structure to allow for medium-term influences did not bring the expected results. A possible explana-

\footnotetext{
${ }^{8}$ The formal causality test is not reported in the SMAR procedure as the $F$-statistics are not reliable in this case. The correlation matrix of innovations capturing instantaneous causality is not shown but available on request.
}

TABLE 2.-VECTOR AUTOREgRESSIVE REPRESENTATION of Exports, Productivity AND Terms of Trade (SMAR-MODEL) $^{\text {a }}$

\begin{tabular}{|c|c|c|c|}
\hline \multirow[b]{2}{*}{ Regressors } & \multicolumn{3}{|c|}{ Dependent Variables ( $t$-values in parentheses) } \\
\hline & $X G$ & $P R O D$ & PTR \\
\hline$X G(1)$ & $\begin{array}{c}-0.44 \\
(4.3)\end{array}$ & & \\
\hline$X G(4)$ & & & $\begin{array}{c}0.11 \\
(2.36)\end{array}$ \\
\hline$X G(5)$ & & & $\begin{array}{c}-0.24 \\
(4.51)\end{array}$ \\
\hline$X G(6)$ & & & $\begin{array}{c}-0.20 \\
(4.36)\end{array}$ \\
\hline$P R O D(2)$ & $\begin{array}{l}0.3 \\
(3.78)\end{array}$ & & \\
\hline $\operatorname{PROD}(4)$ & & & $\begin{array}{c}0.32 \\
(5.25)\end{array}$ \\
\hline $\operatorname{PROD}(6)$ & & & $\begin{array}{r}-0.37 \\
(5.17)\end{array}$ \\
\hline$P R O D(8)$ & & $\begin{array}{c}-0.25 \\
(2.37)\end{array}$ & \\
\hline $\operatorname{PTR}(1)$ & & & $\begin{array}{c}-0.39 \\
(4.45)\end{array}$ \\
\hline $\operatorname{PTR}(2)$ & $\begin{array}{c}-0.44 \\
(2.63)\end{array}$ & & \\
\hline $\operatorname{PTR}(5)$ & & & $\begin{array}{c}-0.23 \\
(2.65)\end{array}$ \\
\hline $\operatorname{PTR}(7)$ & & & $\begin{array}{c}-0.32 \\
(3.87)\end{array}$ \\
\hline$Q(1)$ & $\begin{array}{c}0.63 \\
(2.22)\end{array}$ & $\begin{array}{c}0.34 \\
(2.39)\end{array}$ & \\
\hline$Q(5)$ & $\begin{array}{c}0.58 \\
(2.1)\end{array}$ & & \\
\hline$Q(7)$ & $\begin{array}{c}-0.59 \\
(2.19)\end{array}$ & & \\
\hline$Q(8)$ & & & $\begin{array}{c}0.30 \\
(2.16)\end{array}$ \\
\hline$D 1$ & & $\begin{array}{l}-0.11 \\
(10.75)\end{array}$ & \\
\hline$D 2$ & & $\begin{array}{c}0.11 \\
(10.72)\end{array}$ & \\
\hline D3 & $\begin{array}{c}0.04 \\
(3.61)\end{array}$ & $\begin{array}{l}-0.12 \\
(11.07)\end{array}$ & \\
\hline$D 4$ & $\begin{array}{c}0.04 \\
(4.09) \\
\end{array}$ & $\begin{array}{c}0.17 \\
(11.44) \\
\end{array}$ & \\
\hline$R^{2} C$ & 0.704 & 0.967 & 0.617 \\
\hline SE & 0.03849 & 0.01944 & 0.01866 \\
\hline
\end{tabular}

aAll regressions cover 1966 2-19854

tion for the absence of any causality from exports on productivity is that different effects running in opposite directions might have cancelled. An export stimulus might have increased productivity through the own production and the concentration effect which might have been compensated by an export induced prevention of the rationalization effect to work. Export increases might have induced entry into the market thereby compensating the scale effect on productivity of higher exports. Similar counteracting forces might explain the estimated absence of any causality from the terms of trade on productivity suggested by Krugman (1984). 
It seems, therefore, that the present time series study does not confirm the causal predictions implied by the export-led growth model and is only compatible with some aspects of recent trade theory. Neither an export stimulus nor a deterioration in the terms of trade seem capable of causing a productivity change in Austria as is suggested by the models.

\section{v. Conclusions}

In this paper we have investigated the relationship between productivity and exports based on Austrian data using time series analysis. The causality analysis indicates no causal link from exports to productivity, while the estimated positive causation from productivity to exports seems to be consistent with the causal hypotheses of the theories of intra-industry trade.

The estimated absence of any causal link from exports to productivity on the one hand and from the terms of trade to productivity on the other suggests that disturbances caused by a devaluation of the exchange rate and/or by an import tariff do not seem to be capable of boosting productivity in Austria as implied by the export-led growth and recent trade models. Furthermore, the causality analysis suggests that the gain in Austrian export market shares has been caused by the productivity performance while an explanation for the comparatively high productivity growth in Austria is still open for further research. ${ }^{9}$

The main result of the paper-the rejection of the hypothesis that exports cause productivity based on Austrian data - is however of a preliminary nature and the analysis needs to be extended to other industrialized as well as developing countries before policy implications can be drawn. ${ }^{10}$

\footnotetext{
${ }^{9}$ Between 1963 and 1982 Austria increased its share on world trade by $20.2 \%$.

${ }^{10} \mathrm{~A}$ first finding of an application to other industrialized countries indeed suggests that the export-led growth hypothesis could not be rejected for the United States, Germany, and Japan; see Marin (1988, 1989).
}

\section{REFERENCES}

Akaike, H., "A New Look at the Statistıcal Model Identification." IEEE Transactions on Automatic Control AC-19, Dec. 1974, 716-723.

Ashenfelter, Orley, and David Card, "Time Series Representations of Economic Variables and Alternative Models of the Labour Market," Review of Economic Studies 159 (1982), 761-782.

Balassa, Bela, "Exports and Economic Growth: Further Evidence," Journal of Development Economics 2 (1978), 181-189.

Beckerman, Wilfried, "Demand, Exports and Growth," in W. Beckerman, and Associates, The Brittsh Economy in 1975, The National Institute of Economic and Social Research, 1965, 44-72.

Bhagwati, Jagdish N., Foreign Trade Regımes and Economic Development: Anatomy and Consequences of Exchange Control Regimes (Cambridge: Ballinger, 1978).

Feder, Gershon, "On Exports and Economic Growth," Journal of Development Economics 12 (1982), 59-73.

Granger, Clive W. J., "Investigating Causal Relations by Econometric Models and Cross-spectral Methods," Econometrica 37 (July 1969), 424-438.

Helpman, Elhanan, and Paul Krugman, Market Structure and Foretgn Trade (Cambridge: MIT Press, 1985)

Helpman, Elhanan, and Manuel Trajtenberg, "Dynamic Comparative Advantage and the Hypothesis of Export-led Growth," Tel Aviv University, 1987, mimeo.

Krugman, Paul, Import Protection as Export Promotion in $\mathrm{H}$. Kierzkowski (ed.), Monopolistıc Competition in Internatonal Trade (Oxford: Oxford University Press, 1984), 180-193.

Kunst, Robert, and Klaus Neusser, "A Forecasting Comparison of Some VAR Techniques," International Journal of Forecasting 2 (1986), 447-456.

Leamer, Edward, "Vector Autoregressions for Causal Inference?" Carnegle Rochester Conference Series on Public Polcy 22 (Spring 1985), 255-304.

Marin, Dalia, "Trade and Scale Economes," EUI Working Paper No. 88/332, 1988, European University, Florence.

, "Is the Export-led Growth Hypothesis Valid for Industrialized Countries?" EUI Working Paper No. 89/386, European University, Florence (1989)

Michaely, Michael, "Exports and Growth. An Empirical Investigation," Journal of Development Economics 4 (1977), 49-53.

Sims, Christopher A., "Money, Income and Causality," Amerlcan Economic Review 62 (Sept. 1972), 540-552.

Vernon, Raymond, "International Investment and International Trade in the Product Cycle," Quarterly Journal of Economics 80 (1966), 290-307. 